\title{
Comparison of hormonal and histological changes during follicular growth, as measured by ultrasonography, in cattle
}

\author{
C. A. Price ${ }^{1}$, P. D. Carrière ${ }^{1}$, B. Bhatia ${ }^{1}$ and N. P. Groome ${ }^{2}$ \\ ${ }^{1}$ Centre de recherche en reproduction animale, Faculty of Veterinary Medicine, University of Montreal, \\ St-Hyacinthe, Quebec, Canada; and ${ }^{2}$ School of Biological and Molecular Sciences, Oxford Brookes \\ University, Oxford, UK
}

The aim of the study was to compare histological and endocrinological indices of ovarian follicle health in cattle with monitoring of follicle growth and regression by ultrasound imaging in vivo. Ultrasound scanning was performed daily. Follicles were obtained at ovariectomy; follicular fluid was collected for assay, and the degree of atresia was assessed histologically. Histological atresia was correlated with growth patterns when anovulatory growing and regressing follicles were compared $(P<0.05)$, but was not different between growing and static follicles. Oestradiol concentrations were lower in static than in growing follicles, although the difference was not significant $\left(35 \pm 7\right.$ versus $260 \pm 120 \mathrm{ng} \mathrm{ml}^{-1}$; $P<0.08$ ), and were significantly lower in regressing follicles $\left(7 \pm 5 \mathrm{ng} \mathrm{ml}^{-1} ; P<0.05\right)$. Oestradiol concentrations were significantly lower in histologically atretic than in nonatretic follicles ( $16 \pm 8$ versus $282 \pm 132 \mathrm{ng} \mathrm{ml}^{-1} ; P<0.05$ ), but were not different between nonatretic and early atretic follicles $(P>0.05)$. There was a significant negative correlation between oestradiol concentration and the number of days the follicle was visible by ultrasound $(r=-0.71 ; P<0.001)$. Concentrations of progesterone in follicular fluid were correlated with the number of days the follicles were detected $(r=0.61 ; P<0.01)$ and were higher in regressing than in growing follicles (122 \pm 71 versus $48 \pm 13 \mathrm{ng} \mathrm{ml}^{-1} ; P<0.05$ ) but not significantly higher in atretic compared with nonatretic follicles (129 \pm 102 versus $53 \pm 15 \mathrm{ng} \mathrm{ml}^{-1}$ ). The progesterone:oestradiol ratio was significantly correlated with the number of days a follicle was detected by ultrasound $(r=0.8 ; P<0.001)$ and was significantly higher in regressing than in growing follicles, and higher in atretic than in nonatretic follicles $(P<0.05)$. Concentrations of dimeric inhibin in follicular fluid were not significantly correlated with number of days that a follicle was detected by ultrasound $(P>0.05)$, but were significantly $(P<0.05)$ higher in regressing $\left(3.0 \pm 0.7 \mu \mathrm{g} \mathrm{ml}^{-1}\right)$ than in growing or static follicles $\left(1.2 \pm 0.2\right.$ versus $\left.1.1 \pm 0.2 \mu \mathrm{g} \mathrm{ml}^{-1}\right)$. Inhibin concentrations were not significantly affected by degree of atresia. Oestradiol concentrations of preovulatory follicles were significantly higher than those of regressing follicles (1131 \pm 382 versus $\left.35 \pm 7 \mathrm{ng} \mathrm{ml}^{-1} ; P<0.05\right)$ and concentrations of dimeric inhibin were lower $(1.0 \pm 0.2$ versus $\left.3.9 \pm 0.4 \mu \mathrm{g} \mathrm{ml}^{-1} ; P<0.05\right)$. Oestradiol and inhibin concentrations were negatively correlated $(r=-0.65 ; P<0.05)$. Dimeric inhibin concentrations were similar between growing nonovulatory and presumptive preovulatory follicles $(P>0.05)$. These results demonstrate that growing follicles contain high oestradiol and low progesterone and dimeric inhibin concentrations and that, as the rate of growth of the follicle slows, oestradiol concentrations decrease, but progesterone and dimeric inhibin concentrations do not increase until the follicle starts to regress. Histological indices of atresia did not closely correlate with either morphological or endocrinological measures of follicular growth.

\section{Introduction}

The health of ovarian follicles in ruminants has been examined at three levels: morphological, histological and endocrinological. Morphologically healthy follicles are characterized by a

Revised manuscript received 18 August 1994 highly vascularized theca, a dense granulosa cell layer and clear follicular fluid (McNatty et al., 1984; Tsonis et al., 1984). Histological studies have defined several degrees of atresia, and a useful three-class system identifies nonatretic, early atretic and atretic follicles based on the number of pycnotic nuclei, thickness of granulosa cell layer and basement membrane integrity (Grimes et al., 1987; Spicer et al., 1987). Hormone 
concentrations in follicular fluid are also used to indicate the health of the follicle. Nonatretic follicles contain higher oestradiol and lower progesterone concentrations than do atretic follicles (Webb and England, 1982; Ireland and Roche, 1983; McNatty et al, 1984). Total immunoreactive inhibin concentrations are higher in nonatretic than in atretic follicles (Martin et al., 1991; Guilbault et al., 1993), whereas concentrations of the $\alpha-\beta$ dimer are higher in atretic follicles (Guilbault et al., 1993; Hopko Ireland et al., 1994).

Attempts to define the earliest stages of atresia with the above techniques have met with limited success. In sheep, histologically atretic follicles secreted significantly less oestradiol than did healthy follicles, but there were no clear differences between healthy and early atretic follicles (Tsonis et al., 1984). Similar data have been presented for cattle (McNatty et al., 1984; Grimes et al., 1987), although it was proposed that progesterone concentrations are higher in early atretic than in healthy follicles (Spicer et al., 1987).

The dynamics of bovine follicular growth and regression have been characterized in vivo by ultrasonography (Savio et al., 1988; Sirois and Fortune, 1988). Nonovulatory, large antral follicles essentially go through three stages: a growing phase, a static phase, during which there is no overall change in follicular diameter, and a regressing phase. Large growing follicles contain more oestradiol than do large regressing follicles (Guilbault et al., 1993), and the oestradiol content is higher during the early growth phase, compared with the mid- to late growth phase (Badinga et al., 1992). Total inhibin immunoactivity is higher in growing than in regressing follicles (Martin et al., 1991; Guilbault et al., 1993), whereas dimeric inhibin is higher in regressing than in growing follicles (Guilbault et al., 1993). Information regarding the endocrinological or histological status of static follicles is not available.

The aim of the present study was to compare the histological and endocrinological profiles during growth and regression of bovine follicles, with particular emphasis on follicles in the static phase of development.

\section{Materials and Methods}

\section{Animals and treatments}

Crossbred Holstein heifers were housed indoors at the CRRA farm in St-Hyacinthe, Quebec (latitude $45^{\circ} 30^{\prime} \mathrm{N}$ ), and were maintained under normal husbandry conditions. Detection of oestrus was conducted twice a day to verify that the animals were displaying normal oestrous cycles before use. All animals were examined daily by transrectal ultrasonography (5 MHz probe; LS300A: Tokyo Keiki Co., Tokyo) beginning before the onset of the study cycle, and the images were recorded on videotape to monitor the development of follicles greater than $5 \mathrm{~mm}$ in diameter.

Nonovulatory growing, static and regressing follicles were obtained by removing the largest follicle from the ovary of 25 cows immediately after flank ovariectomy (paravertebral block at L1, L2 and L3 with $15 \mathrm{ml} 2 \%(\mathrm{v} / \mathrm{v})$ lidocaine; MTC Pharmaceutical, Canada) between day 5 and day 19 of the oestrous cycle, when the dominant follicle was clearly distinguishable by ultrasound. The fluid was aspirated and centrifuged at $1000 \mathrm{~g}$ for $5 \mathrm{~min}$ to remove cell debris, and segments of the follicle wall were fixed in Bouin's solution. These follicles were retrospectively classed as 'growing' (increasing in size), 'static' (no change in follicle size over at least 2 days) or 'regressing' (decreasing in diameter). This classification is herein referred to as follicular status. The duration of detection is defined as the number of days a given follicle was detected by ultrasound.

Preovulatory follicles were obtained by giving six heifers a luteolytic dose of $\mathrm{PGF}_{2 \alpha}(500 \mu \mathrm{g}$; Estrumate: Coopers Agropharm Inc., Ajax, Ontario) on day 13 of the cycle (day $0=$ oestrus), and the ovaries removed when the presumptive preovulatory follicle was clearly distinguishable by ultrasound examination (between day 2 and day 4 after prostaglandin administration). Follicular fluid was aspirated from the preovulatory follicle and from the regressing previously dominant follicle, and segments of follicle wall were fixed in Bouin's solution.

These studies were conducted in accordance with the Canadian Council on Animal Care and were approved by the Animal Ethics Committee of the Faculty of Veterinary Medicine.

\section{Histology}

Sections embedded in paraffin wax were placed on poly-Llysine coated slides and pretreated with xylene and ethanol. Several sections of each follicle were stained with eosin and haematoxylin and were examined by microscope by two observers. The follicles were classified into one of three groups based on published criteria (Grimes et al., 1987; Spicer et al., 1987): nonatretic follicles had at least seven layers of granulosa cells, an intact basement membrane and few pycnotic nuclei; early atretic follicles had two to six layers of granulosa cells, numerous pycnotic nuclei and a loosening of the basement membrane; and atretic follicles had fewer than two layers of granulosa cells and complete disruption of basement membrane integrity. This classification is herein referred to as follicular atresia.

\section{Assays}

Samples of fluid from growing and static follicles were assayed for oestradiol and progesterone after chromatography on C-18 and LH-20 columns, as described by Bélanger et al. (1990). Samples from preovulatory follicles were assayed for oestradiol without extraction. Preliminary experiments using a variety of samples containing 100 to $2500 \mathrm{ng}$ oestradiol $\mathrm{ml}^{-1}$ showed significant correlation between extracted and nonextracted assays $(r=0.9 ; P<0.001)$. Intra-assay coefficients of variation $(\mathrm{CV})$ were calculated from five control samples and were less than 7 and $9 \%$ for progesterone and oestradiol, respectively. Interassay $\mathrm{CV}$ for samples containing 24 and $115 \mathrm{ng}$ progesterone $\mathrm{ml}^{-1}$ were 7 and $11 \%$, respectively, and for samples containing 80 and $500 \mathrm{ng}$ oestradiol $\mathrm{ml}^{-1}$ were 13 and $24 \%$, respectively.

Samples from all follicles were assayed for dimeric inhibin with antibodies described by Groome (1991). Briefly, Nunc 


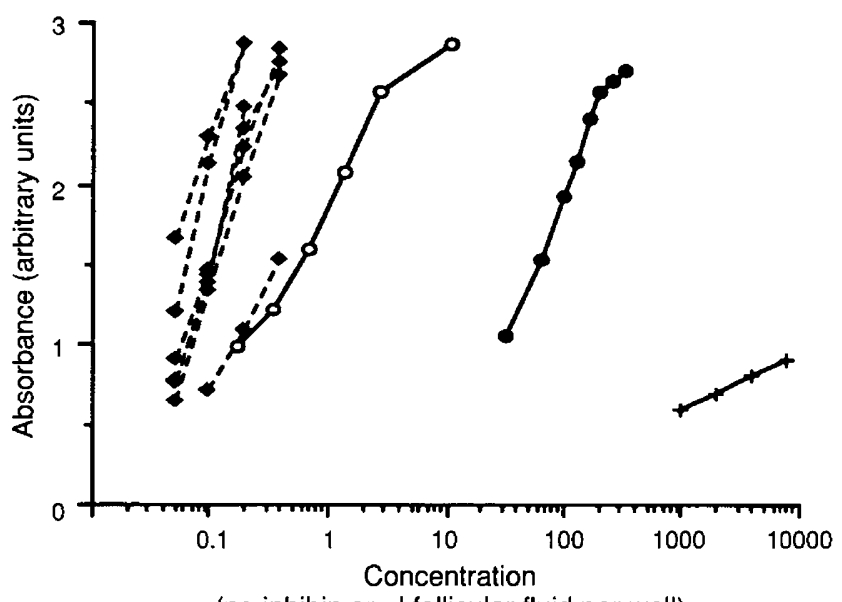

(pg inhibin or $\mu$ follicular fluid per well)

Fig. 1. Validation of the two-site enzyme-linked immunosorbent assay (ELISA) for dimeric inhibin for use in cattle. Standard curves for (0) recombinant human inhibin and $(\bullet)$ native $32 \mathrm{kDa}$ bovine inhibin are shown, with the crossreaction of $(+)$ recombinant human activin. $(\bullet)$ Dilutions of samples from individual follicles show parallelism with the standard curves.

Immunoplates (type 1 ; Gibco BRL Inc, Burlington, Ont) were coated with $200 \mu \mathrm{l} 2.5 \mu \mathrm{g}$ antibody $\mathrm{R}^{-1 \mathrm{ml}^{-1}}$ (anti- $\alpha$ subunit) in

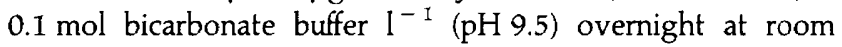
temperature, after which the wells were blocked with $1 \%$ protease-free BSA (Sigma Chemical Co., St Louis, MO) in $0.05 \mathrm{~mol} \mathrm{PBS}^{-1}, \mathrm{pH} 7.5$ for $3 \mathrm{~h}$. Wells were washed eight times with $200 \mu \mathrm{l} 0.05 \mathrm{~mol}$ PBS $\mathrm{l}^{-1}$ with $0.05 \%$ Tween 80 (Sigma Chemical Co.), and then once again in PBS only. Standards or samples were diluted in PBS with $1 \%(w / v)$ protease-free BSA and $0.5 \%$ Tween 80 , and were added in $100 \mu \mathrm{l}$ aliquots and incubated overnight at room temperature. After incubation, the wells were washed four times as above. Biotinylated antibody E4 (anti- $\beta$ subunit) was then added (100 $\mu \mathrm{l}$ of $\left.2.5 \mu \mathrm{g} \mathrm{ml}^{-1}\right)$, and after $1 \mathrm{~h}$ incubation the plates were washed four times as above, and $100 \mu \mathrm{l}$ of 1:5000 streptavidin:alkaline phosphatase (Boehringer Mannheim Canada Inc., Laval, Quebec) was added in $0.005 \mathrm{~mol}$ Tris- $\mathrm{HCl}$ $1^{-1}, \mathrm{pH} 7.6$, containing $0.15 \mathrm{~mol} \mathrm{NaCl} \mathrm{l}^{-1}$ and $1 \%$ proteasefree BSA. After incubation for $1 \mathrm{~h}$, the wells were washed four times in $0.05 \mathrm{~mol} \mathrm{Tris}-\mathrm{HCl} \mathrm{l}^{-1}, \mathrm{pH} \mathrm{7.6}$, containing $0.15 \mathrm{~mol}$ $\mathrm{NaCl} l^{-1}$. Bound alkaline phosphatase was detected using an enzyme amplified system (Gibco BRL Inc.), as described by the manufacturer. Native bovine $32 \mathrm{kDa}$ inhibin (Peninsula Laboratories Europe Ltd, St Helens, Merseyside) was used as the routine assay standard; this is approximately 100 times less potent than recombinant human inhibin (Fig. 1). Crossreaction with recombinant human activin was negligible (Fig. 1; recombinant proteins generously provided by Genentech Inc., San Francisco, CA). Recovery of $0.28,0.56,1.12$ and $2.25 \mathrm{pg}$ recombinant $32 \mathrm{kDa}$ inhibin from a 1:1000 dilution of bovine follicular fluid in assay buffer were 107, 109, 102 and 117\%, respectively (mean of $108 \%$ ). For a more rigorous test of possible interference by binding proteins, the same quantities of recombinant inhibin were added to a 1:2 dilution of plasma from an ovariectomized cow and to a solution of $0.4 \mathrm{mg}$ $\alpha_{2}$-macroglobulin $\mathrm{ml}^{-1}$ (Sigma Chemical Co.); mean recoveries were 94 and $90 \%$, respectively. Samples of follicular fluid were routinely assayed in triplicate at four different dilutions ( $1: 250$, 1:500, 1:1000 and 1:2000), and were parallel to the standard curve (Fig. 1). A standard curve and quality control samples were run on each plate. The mean intra- and interassay CVs were $8 \%$ and $10 \%$, respectively, based on samples containing 1.2 and $2.3 \mu \mathrm{g} \mathrm{ml}^{-1}$. The sensitivity of the assay was equivalent to $0.1 \mu \mathrm{g} 32 \mathrm{kDa}$ inhibin $\mathrm{ml}^{-1}$ follicular fluid.

\section{Statistical analyses}

Concentrations of hormones assayed in follicular fluid were log transformed before analysis to obtain a normal distribution (Shapiro-Wilk test). Hormone concentrations were analysed by least-squares analysis of variance with follicular status (growing, static, regressing), atresia (nonatretic, early atretic, atretic), duration of detection, day of cycle, and follicle diameter at ovariectomy in the mathematical model. For comparison with previous studies, hormone concentrations were then tested for effects of follicular status and of atresia separately. Relationships between follicular status and degree of atresia were tested by analysis of loglikelihood. All analyses were performed using JMP (SAS for the Macintosh; SAS Institute Inc., Cary, NC). All data are presented as arithmetic means \pm SEM.

\section{Results}

\section{Nonovulatory follicles}

For nonovulatory follicles, nine growing, eleven static and five regressing follicles were obtained. Ovariectomies were performed on the following days of the oestrous cycle, with the number of cows at each time point in parentheses: day 5 (3), $6(5), 7(4), 8(2), 9(3), 10(2)$, and then one cow on each of days $11,12,13,15,18$ and 19. The average duration of detection was $5.3 \pm 0.5,7.0 \pm 0.5$ and $12.2 \pm 0.7$ days for growing, static and regressing follicles, respectively $(P<0.05)$. Growing follicles were mainly (67\%) nonatretic, and three of nine were classed as early atretic. Of the static follicles, four were histologically nonatretic, five were early atretic and two were atretic. Regressing follicles consisted of three early atretic and two atretic follicles. The degree of atresia differed significantly between growing and regressing follicles $(P<0.05)$, but not between growing and static follicles.

Analysis of variance indicated that oestradiol concentrations were affected significantly by the duration of detection $(P<0.05)$. There was a significant negative correlation between oestradiol and the number of days a follicle was detected $(r=-0.71 ; P<0.001)$. When each follicle classification was considered separately, oestradiol concentrations were lower in regressing follicles than in growing or static follicles (Fig. 2; $P<0.05$ ), and significantly lower in atretic than in nonatretic follicles (Fig. 2; $P<0.05$ ). There was no significant difference between early atretic and nonatretic follicles $(P>0.05)$, but the difference between static and growing follicles approached significance $(P<0.08)$.

Progesterone concentrations in follicular fluid correlated with the duration of detection of the follicles $(r=0.61$; $P<0.01$ ), and were significantly higher in regressing than in growing follicles (Fig. 2; $P<0.05$ ), but were not significantly 

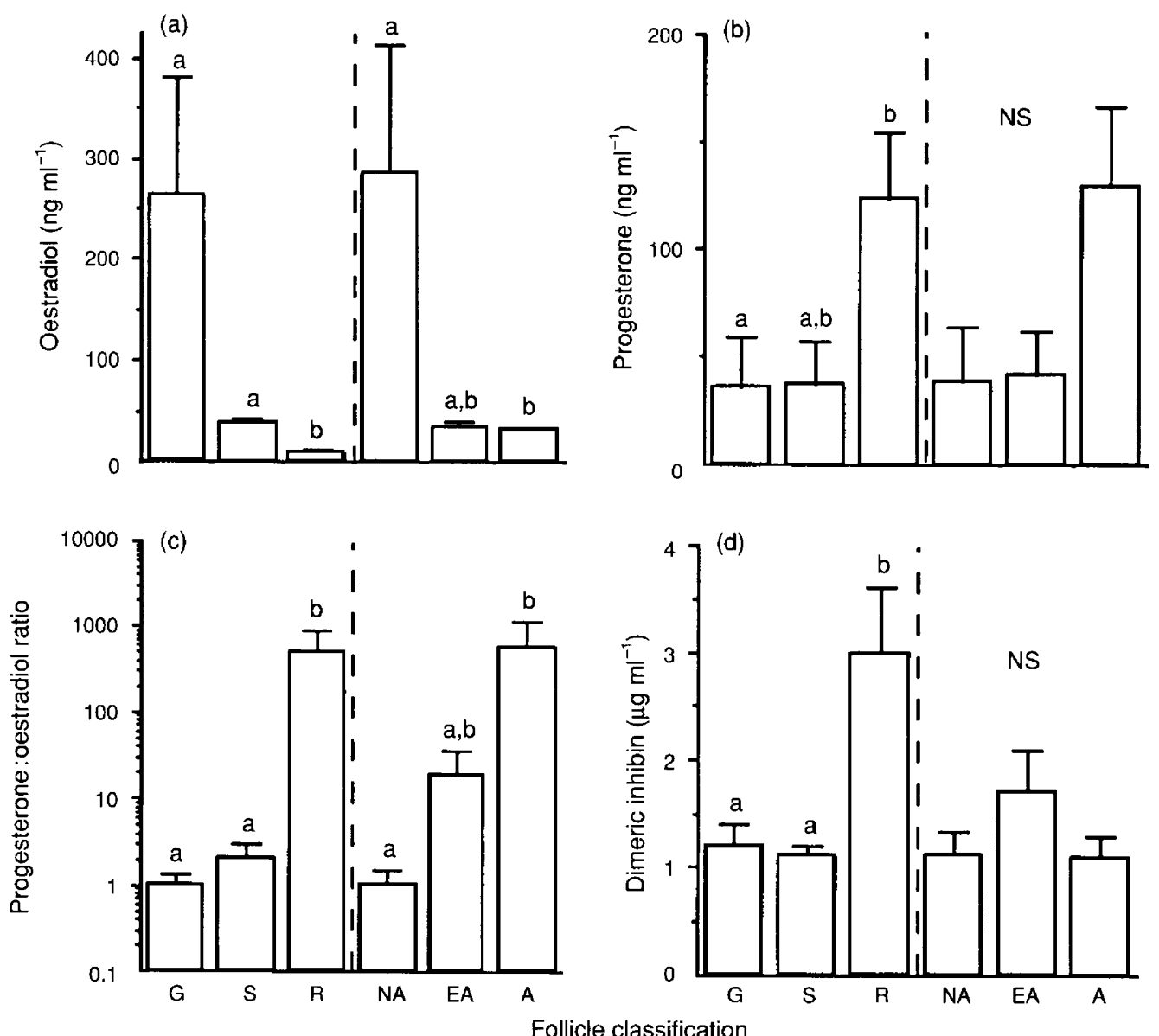

Fig. 2. Effect of follicular status and degree of atresia on (a) concentration of oestradiol, (b) concentration of progesterone, (c) the progesterone:oestradiol ratio and (d) concentration of dimeric inhibin in large, nonovulatory first-wave follicles from cows. Follicles were classed as growing $(\mathrm{G} ; n=9)$, static $(S ; n=11)$ or regressing $(\mathrm{R} ; n=5)$ on the basis of daily ultrasound examination. NA: nonatretic follicles $(n=10)$, EA: early atretic follicles $(n=11)$ and $A$ : atretic follicles $(n=4)$. Columns with different letters above them are significantly different $(P<0.05)$ within classification type. NS: no significant differences between follicle groups.

different between the stages of atresia. Oestradiol and progesterone concentrations were negatively correlated $(r=-0.69 ; P<0.001)$. The progesterone:oestradiol ratio was significantly correlated with duration of detection of follicles $(r=0.8 ; P<0.001)$, and was significantly higher in regressing than in growing or static follicles (Fig. $2 ; P<0.05$ ) and in atretic compared with nonatretic follicles (Fig. 2; $P<0.05$ ).

Concentrations of dimeric inhibin were significantly higher in regressing than in growing or static follicles (Fig. 2; $P<0.05$ ), but not different between growing and static follicles $(P>0.05)$. Inhibin concentrations were not significantly related to the degree of histological atresia (Fig. 2; $P>0.05$ ). There was no significant correlation between dimeric inhibin and the number of days a follicle was detected $(P>0.05)$. There was a significant negative correlation between inhibin and oestradiol $(r=-0.51 ; P<0.05)$, but not between inhibin and progesterone $(r=0.29 ; P>0.05)$, although a correlation between inhibin and the progesterone:oestradiol ratio approached significance $(r=0.42 ; P=0.06)$.

There was no effect of follicle diameter on concentrations of follicular fluid hormones $(P>0.05)$.

\section{Preovulatory follicles}

Presumptive preovulatory follicles contained significantly higher oestradiol and lower inhibin concentrations $(P<0.05)$ than did regressing follicles (Fig. 3). Oestradiol and inhibin were negatively correlated $(r=-0.65 ; P<0.05)$. Preovulatory follicles $(n=6)$ were histologically nonatretic and the regressing follicles were early atretic $(n=4)$ or atretic $(n=2)$, and the effect of atresia on oestradiol and inhibin concentrations was significant $(P<0.05)$. Concentrations of dimeric inhibin were not different between preovulatory $\left(1.0 \pm 0.2 \mu \mathrm{g} \mathrm{ml}^{-1}\right)$ and nonovulatory growing or static follicles (1.2 \pm 0.2 and $1.1 \pm 0.2 \mu \mathrm{g} \mathrm{ml}^{-1}$, respectively; $P>0.05$ ), or between regressing first-wave follicles and regressing follicles in preovulatory ovaries $\left(3.0 \pm 0.7\right.$ and $3.9 \pm 0.4 \mu \mathrm{g} \mathrm{ml}^{-1}$, respectively).

\section{Discussion}

The aim of the present study was to compare histological and endocrinological indices of follicular health with growth stage 


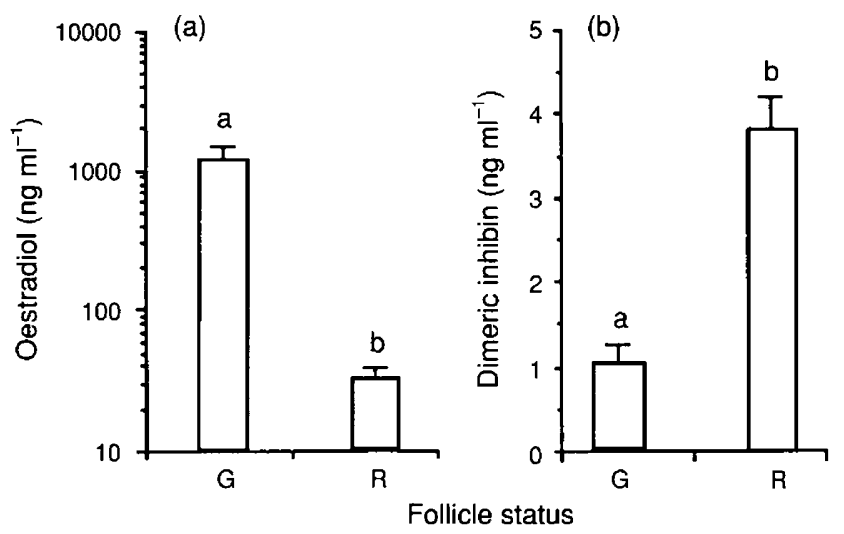

Fig. 3. Effect of stage of follicular growth on concentrations of (a) oestradiol and (b) dimeric inhibin in bovine follicular fluid after prostaglandin-induced luteolysis. Follicles were classed as preovulatory growing $(\mathrm{G} ; n=6)$ or regressing follicles $(\mathrm{R} ; n=6)$ on the basis of daily ultrasound imaging of ovaries. Columns with different letters above them are significantly different $(P<0.05)$.

as determined by ultrasound monitoring of individual dominant follicles in vivo. The results indicate that endocrine parameters agree well with phase of growth, but that histological indices do not correlate well with the endocrine or ultrasound data.

The degree of atresia did not have a significant main effect on concentrations of follicular hormones in first-wave follicles in this study, owing primarily to the overlap of histologically nonatretic and early atretic follicles across phases of follicular growth. This finding suggests that individual follicles may manifest divergent rates of histological and endocrinological change. Thus, a particular growing follicle may be oestrogenically competent yet contain a relatively high number of pycnotic nuclei. However, this type of histology is probably the least reliable classification method, as weaknesses involved in this procedure include subjectivity, tissue damage during processing (particularly after fluid aspiration as in the present study), and the very small part of the follicle actually examined. This discrepancy between histological and endocrinological indices in follicles has been noted for several species (Hay et al., 1976; Ireland and Roche, 1982; Koering et al., 1982), and is supported by the present results from ultrasound studies in cattle. The results reported here demonstrate that growing, static and regressing follicles do not represent nonatretic, early atretic and atretic follicles, respectively.

Histological indices accurately reflected the ultrasound classification when preovulatory and regressing follicles were compared. This was probably facilitated by considering only two classes of follicle status, and by the clear physiological difference between regressing, previously dominant, follicles and rapidly growing preovulatory follicles. Similarly, comparison of growing nonovulatory and clearly regressing follicles showed a distinct separation of nonatretic and atretic follicles (Guilbault et al., 1993; present study). The results reported here are in agreement with previous studies in showing a difference in oestradiol concentration between nonatretic and atretic bovine follicles (McNatty et al., 1984; Grimes et al., 1987; Spicer et al., 1987; Guilbault et al., 1993), although they did not indicate differences between nonatretic and early atretic follicles.

The observed linear decrease in oestradiol concentrations in follicular fluid with time after emergence of the follicle wave extends the observations of Badinga et al. (1992), who showed a decrease in oestradiol in follicular fluid from day 5 to day 8 of the cycle and no further decrease between day 8 and day 12 . Some follicles in the present study contained relatively little oestradiol as they neared the end of their growth phase, although they were classified as growing. This would account for the large variation in oestradiol concentrations in follicular fluid in growing follicles, and would suggest why the apparent difference between growing and static follicles did not reach significance.

The negative correlation between oestradiol concentrations in follicular fluid and time in first-wave follicles in the present study indicates that few, if any, of the follicles were collected during peak oestradiol production. It can be assumed, therefore, that peak production occurs on or before day 5 of the oestrous cycle. This correlation also suggests that oestradiol secretion is declining following the withdrawal of folliculogenic stimuli, such as increased LH and FSH signals present during the first few days of the oestrous cycle, when LH pulse frequency is higher than the luteal phase average (Rahe et al., 1980; Walters et al., 1984) and there is a short-lived increase in FSH concentrations (Adams et al., 1992).

In agreement with previous studies, progesterone concentrations in follicular fluid were higher in regressing than in growing follicles, and were higher in atretic compared with nonatretic follicles (Webb and England, 1982; Ireland and Roche, 1983; McNatty et al., 1984; Guilbault et al., 1993). Although the difference between nonatretic and atretic follicles failed to reach significance in the present study, it is clear from the results that progesterone concentrations in follicular fluid did not differ between nonatretic and early atretic follicles, as shown by McNatty et al. (1984) and Grimes et al. (1987). The progesterone:oestradiol ratio shows more clearly the progression from oestradiol-dominated to progesterone-dominated follicles as follicles ceased to grow and became more atretic. Nevertheless, these results strongly suggest that progesterone concentrations of growing and static follicles are not different.

The concentrations of dimeric inhibin in follicular fluid determined in this study are in agreement with those measured by Guilbault ef al. (1993) for growing and regressing follicles. These results have been extended by the present study, which has shown that the inhibin concentrations of static follicles and growing preovulatory follicles are similar to those of growing nonovulatory follicles. Concentrations of dimeric inhibin are therefore high only in regressing follicles. Since such follicles possess few or no granulosa cells (the presumed source of the inhibin), the accumulation of inhibin in follicular fluid is possibly a consequence of granulosa cell breakdown and subsequent release of the stored hormone into the antral fluid. Alternatively, certain proteins may become concentrated in follicular fluid as the follicle decreases in diameter and contains a smaller volume of fluid (Wise, 1987). However, there was no significant effect of follicle size on any hormone examined in the present study. The clearance rate of inhibin from follicular fluid is unknown, although the clearance from ovine follicles of another dimeric glycoprotein, LH, appears to be slow 
(McNatty et al., 1981). Another possibility is the metabolism or degradation of precursor inhibin molecules into the mature dimer within the follicular fluid of regressing follicles. Certainly, many inhibin molecules are present in follicular fluid, and quantities of different forms of inhibin differ between healthy and atretic follicles (Hopko Ireland et al., 1994).

Low concentrations of oestradiol in follicular fluid have been used as a marker for atretic follicles, but the present results indicate that static follicles, containing lower oestradiol concentrations, may not all be truly atretic. Turzillo and Fortune (1993) suggested that reinstatement of an appropriate FSH stimulus to static follicles reactivates oestradiol secretion and growth of follicles. Dimeric inhibin concentrations, in contrast, were high in regressing first-wave follicles, and these follicles were more likely to be atretic. It is not known whether regressing follicles can be rescued from atresia, although follicles do not ovulate if they are regressing when luteolysis occurs (Quirk et al., 1986). Increased inhibin concentrations may thus be a good marker for follicular regression, and may be used in conjunction with oestradiol and progesterone concentrations to differentiate between growing or static follicles and regressing follicles.

In summary, this study has shown that histological indices of atresia do not correlate well with the stage of follicular growth and regression as determined either in vivo by ultrasound scanning of ovaries or by assessment of follicular concentrations of oestradiol, progesterone and dimeric inhibin. There is, however, good agreement between these endocrine correlates and stage of development as assessed by ultrasound. In addition, concentrations of dimeric inhibin in follicular fluid were not different between nonovulatory growing and static, first-wave follicles and preovulatory growing follicles, and were increased only in regressing follicles. Whether this increase in dimeric inhibin has any functional significance has yet to be determined.

The authors thank N. Houle and his staff for care of the animals, and D. Harvey and P. Guay for performing the ovariectomies. We are indebted to A. Bélanger for providing oestradiol antibody and performing the steroid assays in Expt I, and to J. P. Mather of Genentech Inc. for providing recombinant inhibin and activin. This work was supported by Fonds FCAR of Quebec (C. A. Price), NSERC of Canada (C. A. Price and P. D. Carrière), the Cancer Research Campaign (N. P. Groome) and the UK Medical Research Council (N. P. Groome).

\section{References}

Adams GP, Matteri RL, Kastelic JP, Ko JCH and Ginther OJ (1992) Association between surges of follicle-stimulating hormone and the emergence of follicular waves in heifers Journal of Reproduction and Fertility 94 177-188

Badinga L, Driancourt MA, Savio JD, Wolfenson D, Drost M, de la Sota RL and Thatcher WW (1992) Endocrine and ovarian responses associated with the first-wave dominant follicle in cattle Biology of Reproduction 47 871-883

Bélanger A, Couture J, Caron S and Roy R (1990) Determination of nonconjugated and conjugated steroid levels in plasma and prostate after separation on C-18 columns Annals of the New York Academy of Sciences 595 251-259

Grimes RW, Matton P and Ireland JJ (1987) A comparison of histological and non-histological indices of atresia and follicular function Biology of Reproduction $3782-88$
Groome N (1991) Ultrasensitive two-site assays for inhibin-A and activin-A using monoclonal antibodies raised to synthetic peptides Journal of Immunological Methods 145 65-69

Guilbault LA, Rouillier P, Matton P, Glencross RG, Beard AJ and Knight PG (1993) Relationships between the level of atresia and inhibin contents ( $\alpha$ subunit and $\alpha-\beta$ dimer) in morphologically dominant follicles during their growing and regressing phases of development in cattle Biology of Reproduction 48 268-276

Hay MF, Cran DG and Moor RM (1976) Structural changes occurring during atresia in sheep ovarian follicles Cell and Tissue Research 169 515-529

Hopko Ireland JL, Good TEM, Knight PG and Ireland JJ (1994) Alterations in amounts of different forms of inhibin during follicular atresia Biology of Reproduction 50 1265-1276

Ireland JJ and Roche JF (1982) Development of antral follicles in cattle after prostaglandin-induced luteolysis: changes in serum hormones, steroids in follicular fluid, and gonadotropin receptors Endocrinology 111 2077-2086

Ireland JJ and Roche JF (1983) Development of nonovulatory antral follicles in heifers: changes in steroids in follicular fluid and receptors for gonadotropins Endocrinology 112 150-156

Koering MJ, Goodman AL, Williams RF and Hodgen GD (1982) Granulosa cell pyknosis in the dominant follicle of monkeys Fertility and Sterility 37 837-844

McNatty KP, Dobson C, Gibb M, Kieboom L and Thurley DC (1981) Accumulation of luteinizing hormone, oestradiol and androstenedione by sheep ovarian follicles in vivo Journal of Endocrinology 91 99-109

McNatty KP, Heath DA, Henderson KM, Lun S, Hurst PR, Ellis LM, Montgomery GW, Morrison L and Thurley DC (1984) Some aspects of thecal and granulosa cell function during follicular development in the bovine ovary Journal of Reproduction and Fertility 72 39-53

Martin TL, Fogwell RL and Ireland JJ (1991) Concentrations of inhibins and steroids in follicular fluid during development of dominant follicles in heifers Biology of Reproduction 44 693-700

Quirk SM, Hickey GJ and Fortune JE (1986) Growth and regression of ovarian follicles during the follicular phase of the oestrous cycle in heifers undergoing spontaneous and PGF-2 $\alpha$-induced luteolysis Journal of Reproduction and Fertility $77211-219$

Rahe CH, Owens RE, Fleeger JL, Newton HJ and Harms PG (1980) Pattern of plasma luteinizing hormone in the cyclic cow: dependence upon the period of the cycle Endocrinology $107498-503$

Savio JD, Keenan L, Boland MP and Roche JF (1988) Pattern of growth of dominant follicles during the oestrous cycle of heifers journal of Reproduction and Fertility $83663-671$

Sirois J and Fortune JE (1988) Ovarian follicular dynamics during the estrous cycle in heifers monitored by real-time ultrasonography Biology of Reproduction 39 308-317

Spicer LJ, Matton P, Echternkamp SE, Convey EM and Tucker HA (1987) Relationships between histological signs of atresia, steroids in follicular fluid, and gonadotropin binding in individual bovine antral follicles during postpartum anovulation Biology of Reproduction 36 890 898

Tsonis CG, Carson RS and Findlay JK (1984) Relationship between aromatase activity, follicular fluid oestradiol-17 $\beta$ and testosterone concentrations, and diameter and atresia of individual ovine follicles Joumal of Reproduction and Fertility 72 153-163

Turzillo AM and Fortune JE (1993) Effects of suppressing plasma FSH on ovarian follicular dominance in cattle Journal of Reproduction and Fertility $\mathbf{9 8}$ 113-119

Walters DL, Schams D and Schallenberger E (1984) Pulsatile secretion of gonadotrophins, ovarian steroids and ovarian oxytocin during the luteal phase of the oestrous cycle in the cow Journal of Reproduction and Fertility 71 479-491

Webb R and England BG (1982) Identification of the ovulatory follicle in the ewe: associated changes in follicular size, thecal and granulosa cell LH receptors, antral fluid steroids and circulating hormones during the preovulatory period Endocrinology $110873-881$

Wise T (1987) Biochemical analysis of bovine follicular fluid: albumin, total protein, lysosomal enzymes, ions, steroids and ascorbic acid content in relation to follicular size, rank, atresia classification and day of estrous cycle Journal of Animal Science 64 1153-1169 